\title{
Validation of Lanthanide Chiral Shift Reagents for Determination of Absolute Configuration: Total Synthesis of Glisoprenin A
}

\author{
SUPPORTING INFORMATION
}

Christopher M. Adams, Indranath Ghosh, Yoshito Kishi*

Department of Chemistry and Chemical Biology,

Harvard University, Cambridge, MA 02138 


\section{Materials and Methods}

Except as otherwise indicated, reactions were carried out under an argon atmosphere in flame- or oven-dried glassware. Reagents and solvents are commercial grade and were used as supplied, with the following exceptions: THF was distilled from sodium/benzophenone; diethyl ether and dichloromethane were purified by passing through two alumina (A-2) columns using the J. C. Myer (Glass Contour) system; hexamethylphosphoramide (HMPA) was distilled from calcium hydride and stored over $3 \AA \mathrm{MS}$; and triethylamine was distilled from calcium hydride and stored over potassium hydroxide. Reactions were monitored by thin layer chromatography (TLC) with 0.25-mm E. Merck pre-coated silica gel plates. Silica gel 60 for flash chromatography (particle size $0.040-0.063 \mathrm{~mm}$ ) was supplied by EMD. Yields refer to chromatographically and spectroscopically pure compounds unless otherwise noted. ${ }^{1} \mathrm{H}$ and ${ }^{13} \mathrm{C}$ spectra were recorded on a Varian Inova $500 \mathrm{MHz}$ or a Varian Mercury $400 \mathrm{MHz}$ spectrometer. Chemical shifts are reported as $\delta$ values (ppm) relative to internal chloroform ( $\delta 7.26)$, benzene $(\delta 7.15)$, methanol ( $\delta$ 3.34), or pyridine $(\delta 7.58)$ for ${ }^{1} \mathrm{H}$ and either chloroform $(\delta 77.0)$, benzene $(\delta 128.0)$, methanol $(\delta$ 49.0), or pyridine $(\delta 150.4)$ for ${ }^{13} \mathrm{C}$. Optical rotations were measured on a Perkin-Elmer model 241 polarimeter. Low- and high-resolution mass spectra were measured at the Harvard University CCB Mass Spectrometry Facility. 


\section{Epoxide (+)-7}

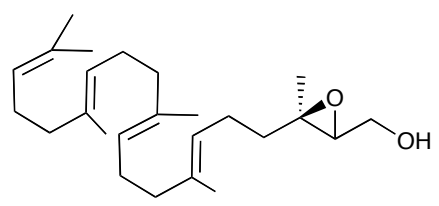

$(+)-7$

Epoxide (+)-7. Epoxide (+)-7 was prepared in accordance with the Sharpless protocol': $[\alpha]_{\mathrm{D}}^{20}+5.4^{\circ}\left(c 1.0, \mathrm{CH}_{2} \mathrm{Cl}_{2}\right) ;{ }^{1} \mathrm{H}$ NMR $\left(500 \mathrm{MHz}, \mathrm{C}_{6} \mathrm{D}_{6}\right) \delta 5.28(\mathrm{~m}, 2 \mathrm{H}), 5.24(\mathrm{~m}, 1 \mathrm{H}), 5.16(\mathrm{dd}, J=$ 6.8, $6.8 \mathrm{~Hz}, 1 \mathrm{H}), 3.51(\mathrm{~m}, 1 \mathrm{H}), 3.44(\mathrm{~m}, 1 \mathrm{H}), 3.44(\mathrm{~m}, 1 \mathrm{H}), 2.81$ (ddd, J = 0, 6.3, $4.9 \mathrm{~Hz}, 1 \mathrm{H})$, $2.66(\mathrm{dd}, J=0,6.8 \mathrm{~Hz}, 1 \mathrm{H}), 2.17(\mathrm{~m}, 6 \mathrm{H}), 2.06(\mathrm{~m}, 8 \mathrm{H}), 1.68(\mathrm{~s}, 3 \mathrm{H}), 1.61(\mathrm{~s}, 6 \mathrm{H}), 1.56(\mathrm{~s}, 3$ $\mathrm{H}), 1.54(\mathrm{~s}, 3 \mathrm{H}), 1.41(\mathrm{~m}, 2 \mathrm{H}), 1.06(\mathrm{~s}, 3 \mathrm{H}) ;{ }^{13} \mathrm{C} \mathrm{NMR}\left(125 \mathrm{MHz}, \mathrm{C}_{6} \mathrm{D}_{6}\right) \delta$ 135.5, 135.1, 135.0, $131.1,124.9,124.8,124.7,124.0,62.9,61.4,60.3,40.20,40.17,40.1,38.8,27.2,27.1$ (2 carbons), 27.0, 25.8, 23.9, 17.7, 16.8, 16.1, 16.0; high resolution mass spectrum (ES+) $\mathrm{m} / \mathrm{z}$ $392.3527\left[\left(\mathrm{M}+\mathrm{NH}_{4}\right)^{+}\right.$; calcd for $\mathrm{C}_{25} \mathrm{H}_{46} \mathrm{O}_{2} \mathrm{~N}$ : 392.3529].

\section{Preparation of Diol (+)-8}

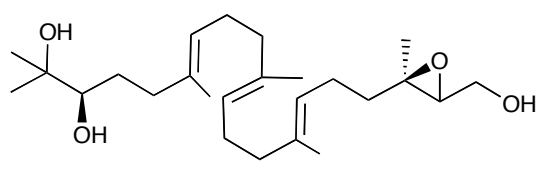

$(+)-8$

Diol (+)-8. To a solution of epoxide (+)-7 (895 mg, $2.39 \mathrm{mmol})$ in $t-\mathrm{BuOH}(12 \mathrm{~mL})$ and $\mathrm{DI}$ $\mathrm{H}_{2} \mathrm{O}(12 \mathrm{~mL})$ was added the Corey-Zhang ligand ${ }^{2,3}(40 \mathrm{mg}, 0.039 \mathrm{mmol})$ and the reaction was placed at $0{ }^{\circ} \mathrm{C}$. Then to the reaction was added $\mathrm{K}_{2} \mathrm{CO}_{3}(990 \mathrm{mg}, 7.17 \mathrm{mmol}), \mathrm{K}_{3} \mathrm{Fe}(\mathrm{CN})_{6}(2.36 \mathrm{~g}$, $7.17 \mathrm{mmol}$ ), $\mathrm{CH}_{3} \mathrm{SO}_{2} \mathrm{NH}_{2}(230 \mathrm{mg}, 2.39 \mathrm{mmol})$ and an aqueous solution $\mathrm{K}_{2} \mathrm{OsO}_{4} \cdot 2 \mathrm{H}_{2} \mathrm{O}$ (ca. $0.3 \mathrm{M}$ $100 \mu \mathrm{L}$, ca. $0.030 \mathrm{mmol})$. The yellow/orange slurry was allowed stirred for $21.5 \mathrm{~h}$ at $0{ }^{\circ} \mathrm{C}$ at which time the reaction was quenched by the addition of $\mathrm{Na}_{2} \mathrm{~S}_{2} \mathrm{O}_{3}(5 \mathrm{~g}), \mathrm{Na}_{2} \mathrm{SO}_{3}(5 \mathrm{~g})$ and water $(40 \mathrm{~mL})$ 
and placed at room temperature. After 45 minutes of stirring the reaction was diluted with ethyl acetate $(100 \mathrm{~mL})$ and the layers separated. The aqueous layer was then re-extracted with ethyl acetate $(2 \times 40 \mathrm{~mL})$. The combined organic layers were then washed sequentially with $2 \mathrm{~N} \mathrm{NaOH}$ (30 mL) and brine $(30 \mathrm{~mL})$, dried with $\mathrm{Na}_{2} \mathrm{SO}_{4}$, filtered and concentrated. Purification via $\mathrm{SiO}_{2}$ gel flash chromatography $\left[40 \rightarrow 75 \%\right.$ ethyl acetate/hexanes, then $8 \% \mathrm{MeOH} / \mathrm{CH}_{2} \mathrm{Cl}_{2}$ (for ligand recovery)] yielded $180 \mathrm{mg}$ of starting epoxide and $600 \mathrm{mg}$ (61\% yield, 77\% BORSM) of diol as an oil: $[\alpha]_{D}^{20}+19.6^{\circ}\left(c 0.5, \mathrm{CH}_{2} \mathrm{Cl}_{2}\right) ;{ }^{1} \mathrm{H}$ NMR $\left(500 \mathrm{MHz}, \mathrm{C}_{6} \mathrm{D}_{6}\right) \delta 5.32(\mathrm{dd}, J=6.6,6.6 \mathrm{~Hz}, 1 \mathrm{H}), 5.27$ (dd, $J=6.8,6.8 \mathrm{~Hz}, 1 \mathrm{H}), 5.18(\mathrm{dd}, J=5.9,5.9 \mathrm{~Hz}, 1 \mathrm{H}), 3.54(\mathrm{~m}, 1 \mathrm{H}), 3.46(\mathrm{~m}, 1 \mathrm{H}), 3.27(\mathrm{~m}, 1$ H), $2.85(\mathrm{dd}, J=4.9,6.4 \mathrm{~Hz}, 1 \mathrm{H}), 2.30(\mathrm{~m}, 1 \mathrm{H}), 2.18(\mathrm{~m}, 5 \mathrm{H}), 2.07(\mathrm{~m}, 7 \mathrm{H}), 1.60(\mathrm{~s}, 7 \mathrm{H}), 1.56$ (m, $1 \mathrm{H}), 1.55(\mathrm{~s}, 3 \mathrm{H}), 1.48(\mathrm{~m}, 2 \mathrm{H}), 1.40(\mathrm{~m}, 3 \mathrm{H}), 1.07(\mathrm{~m}, 9 \mathrm{H}) ;{ }^{13} \mathrm{C}$ NMR $\left(125 \mathrm{MHz}, \mathrm{C}_{6} \mathrm{D}_{6}\right)$ $\delta 135.3,135.2,134.8,125.1,124.9,124.2,78.2,72.7,63.0,61.4,60.5,40.02,39.99,38.8,37.3$, 30.1, 26.7 (2 carbons), 26.3, 23.9, 23.6, 16.7, 16.0, 15.9; high resolution mass spectrum (ES+) $\mathrm{m} / \mathrm{z} 409.3337\left[(\mathrm{M}+\mathrm{H})^{+}\right.$; calcd for $\mathrm{C}_{25} \mathrm{H}_{45} \mathrm{O}_{4}:$ 409.3318].

\section{Preparation of Heptaol (+)-9}

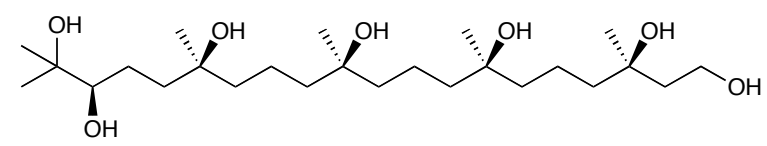

$(+)-9$

Heptaol (+)-9. To a solution of triol (+)-9 (575 mg, $1.41 \mathrm{mmol})$ in acetonitrile $(30 \mathrm{~mL})$ and dimethoxymethane $(57 \mathrm{~mL})$ at $0{ }^{\circ} \mathrm{C}$ was added a $0.05 \mathrm{M}$ buffer solution of $\mathrm{Na}_{2} \mathrm{~B}_{4} \mathrm{O}_{7} \cdot 10 \mathrm{H}_{2} \mathrm{O}$ in $4 \times 10^{-4} \mathrm{M}$ aqueous $\mathrm{Na}_{2}$ EDTA (59 mL), n-Bu $\mathrm{NHSO}_{4}$ (43 mg, $0.126 \mathrm{mmol}$ ), and 1,2,4,5-Di-Oisopropylidene- $\beta$-D-erythro-2,3-hexodiulo-2,6,-pyranose [(Shi catalyst $\left.)^{4} 660 \mathrm{mg}, 2.54 \mathrm{mmol}\right]$. The reaction mixture was then charged simultaneously via two syringe pumps with two solutions: 39 $\mathrm{mL}$ of an aqueous solution of $\mathrm{K}_{2} \mathrm{CO}_{3}(4.25 \mathrm{~g}, 30.55 \mathrm{mmol})$ and $39 \mathrm{~mL}$ of a $4 \times 10^{-4} \mathrm{M}$ aqueous 
$\mathrm{Na}_{2}$ EDTA containing Oxone ${ }^{\circledast}(4.5 \mathrm{~g}, 7.29 \mathrm{mmol})$. The addition of the two solutions was completed over $5 \mathrm{~h}$, at which time the reaction mixture was diluted with water $(50 \mathrm{~mL})$ and ethyl acetate $(300 \mathrm{~mL})$, and the layers were separated. The aqueous layer was then extracted with ethyl acetate $(4 \times 200 \mathrm{~mL})$ dried with $\mathrm{Na}_{2} \mathrm{SO}_{4}$, filtered and concentrated. Purification via $\mathrm{SiO}_{2}$ gel flash chromatography (4\% MeOH/0.6\% $\mathrm{Et}_{3} \mathrm{~N}$ in $\mathrm{CH}_{2} \mathrm{Cl}_{2} \rightarrow 8 \% \mathrm{MeOH} / 0.6 \% \mathrm{Et}_{3} \mathrm{~N}$ in $\mathrm{CH}_{2} \mathrm{Cl}_{2}$ ) yielded $500 \mathrm{mg}(78 \%$ yield $)$ of the tetra-epoxide as an oil.

To a solution of $\mathrm{LiAlH}_{4}(170 \mathrm{mg}, 4.5 \mathrm{mmol})$ in 1,4-dioxane $(8 \mathrm{~mL})$ was added a solution of the tetra-epoxide prepared above (170 $\mathrm{mg}, 0.372 \mathrm{mmol})$ in 1,4-dioxane (4 $\mathrm{mL}$ and $1 \mathrm{~mL}$ wash) via cannula. The heterogeneous mixture was then placed at $90{ }^{\circ} \mathrm{C}$ for $17 \mathrm{~h}$ and then cooled to room temperature and charged with $\operatorname{THF}(7 \mathrm{~mL})$. The reaction was then placed at $0{ }^{\circ} \mathrm{C}$ and a solution of 9:1 THF/ $\mathrm{H}_{2} \mathrm{O}(1.2 \mathrm{~mL})$ was added dropwise, followed sequentially by $2 \mathrm{~N} \mathrm{NaOH}(460 \mu \mathrm{L})$ and $\mathrm{H}_{2} \mathrm{O}(860 \mu \mathrm{L})$. The reaction was put at room temperature and diluted with THF (10 mL) and stirred for 10 minutes, at which time $\mathrm{MgSO}_{4}(1.25 \mathrm{~g})$ was added. The resulting mixture was then filtered through a pad of Celite and the filter cake was washed with $5 \% \mathrm{MeOH} / \mathrm{CH}_{2} \mathrm{Cl}_{2}(3 \times 20 \mathrm{~mL})$. The eluant was concentrated. Purification via $\mathrm{SiO}_{2}$ gel flash chromatography $(12 \rightarrow 20 \%$ $\left.\mathrm{MeOH} / \mathrm{CH}_{2} \mathrm{Cl}_{2}\right)$ yielded $115 \mathrm{mg}(66 \%$ yield $)$ of the heptaol $(+)-9$ as an oil: $[\alpha]_{\mathrm{D}}^{20}+9.0^{\circ}(c 0.6$, MeOH;) ${ }^{1} \mathrm{H}$ NMR (500 MHz, Pyridine-d $\left.\mathrm{d}_{5}\right) \delta 5.6(\mathrm{br} \mathrm{s}, 7 \mathrm{H}), 4.2(\mathrm{~m}, 2 \mathrm{H}), 3.76(\operatorname{app~d}, J=9.8 \mathrm{~Hz}, 1$ H), 2.39 (ddd $J=4.5,12.5,12.5 \mathrm{~Hz}, 1 \mathrm{H}), 2.18(\mathrm{~m}, 2 \mathrm{H}), 1.95(\mathrm{~m}, 9 \mathrm{H}), 1.74(\mathrm{~m}, 12 \mathrm{H}), 1.51$ (s, 3 $\mathrm{H}), 1.48(\mathrm{~s}, 3 \mathrm{H}), 1.43(\mathrm{~s}, 3 \mathrm{H}), 1.42(\mathrm{~s}, 3 \mathrm{H}), 1.38(\mathrm{~s}, 6 \mathrm{H}) ;{ }^{13} \mathrm{C}$ NMR (125 MHz, Pyridine-d $\left.\mathrm{d}_{5}\right)$ $\delta 80.0,72.8,72.2,71.79,71.76,59.3,44.3,44.2,44.1,43.9,43.8,40.8,27.7,27.6,26.9,26.1$, 19.22, 19.18; high resolution mass spectrum (ES+) $\mathrm{m} / \mathrm{z} 465.3788\left[(\mathrm{M}+\mathrm{H})^{+}\right.$; calcd for $\mathrm{C}_{25} \mathrm{H}_{53} \mathrm{O}_{7}$ : 465.3791]. 
Diol (+)-12

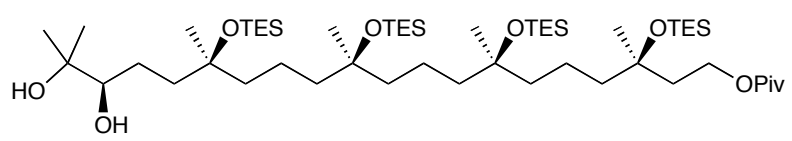

$(+)-12$

Diol (+)-12. To a solution of the corresponding benzylidene acetal (112 mg, $0.102 \mathrm{mmol})$ in ethyl acetate $(3 \mathrm{~mL})$ and ethanol $(350 \mu \mathrm{L})$ under argon was added $\mathrm{Pd}(\mathrm{OH})_{2} / \mathrm{C}[20 \%$ wt $\mathrm{Pd}(14$ mg)]. The argon atmosphere was evacuated and replaced by $\mathrm{H}_{2}$ gas (balloon). After 60 minutes the reaction was complete and was filtered through a pad of Celite and concentrated. Purification via $\mathrm{SiO}_{2}$ gel flash chromatography ( $5 \rightarrow 15 \%$ ethyl acetate/hexanes) yielded $90 \mathrm{mg}$ ( $90 \%$ yield) of the diol (+)-12 as an oil: $[\alpha]_{\mathrm{D}}^{20}+6.0^{\circ}\left(c 0.25, \mathrm{CHCl}_{3} ;\right)^{1} \mathrm{H}$ NMR $\left(500 \mathrm{MHz}, \mathrm{CDCl}_{3}\right) \delta 4.16(\mathrm{~m}, 2 \mathrm{H})$, 3.33 (ddd, $J=3.5,10.5,2.5 \mathrm{~Hz}, 1 \mathrm{H}), 2.67(\mathrm{~d}, J=4.0 \mathrm{~Hz}, 1 \mathrm{H}), 2.15(\mathrm{~s}, 1 \mathrm{H}), 1.76(\mathrm{~m}, 3 \mathrm{H}), 1.56$ (m, $2 \mathrm{H}), 1.35(\mathrm{~m}, 19 \mathrm{H}), 1.23(\mathrm{~s}, 3 \mathrm{H}), 1.21(\mathrm{~s}, 6 \mathrm{H}), 1.19(\mathrm{~s}, 9 \mathrm{H}), 1.16(\mathrm{~s}, 9 \mathrm{H}), 0.95(\mathrm{~m}, 36 \mathrm{H})$, $0.58(\mathrm{~m}, 24 \mathrm{H}), ;{ }^{13} \mathrm{C}$ NMR $\left(125 \mathrm{MHz}, \mathrm{CDCl}_{3}\right) \delta 178.6,79.1,76.0,75.51,75.49,74.5,73.0,61.5$, $43.9,43.22,43.17,43.14,43.07,42.95,40.5,39.1,38.6,27.9,27.8,27.6,27.2,26.5,25.9,23.3$, $19.08,18.98,18.95,7.2,7.18,7.14,7.12,6.92,6.82,6.80 ;$ high resolution mass spectrum (ES+) $m / z 1005.7832\left[(\mathrm{M}+\mathrm{H})^{+} ;\right.$calcd for $\mathrm{C}_{54} \mathrm{H}_{116} \mathrm{O}_{8} \mathrm{Si}_{4}:$ 1005.7825].

\section{Preparation of Olefin (-)-13}

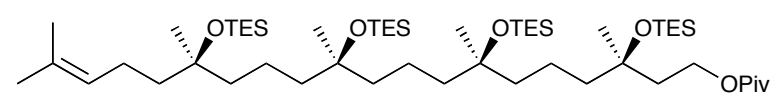

$(-)-13$

Olefin (-)-13. To a solution of diol $(+)-12(93 \mathrm{mg}, 0.09 \mathrm{mmol})$ in THF $(8 \mathrm{~mL})$ at $0{ }^{\circ} \mathrm{C}$ was added $\mathrm{Pb}(\mathrm{OAc})_{4}(80 \mathrm{mg}, 0.18 \mathrm{mmol})$. The reaction was allowed to stir for 10 minutes and then was diluted with sat. aq. $\mathrm{NaHCO}_{3}(10 \mathrm{~mL}), \mathrm{H}_{2} \mathrm{O}(10 \mathrm{~mL})$, and $\mathrm{Et}_{2} \mathrm{O}(50 \mathrm{~mL})$. The layers were separated and the aqueous layer was re-extracted with $\mathrm{Et}_{2} \mathrm{O}(1 \times 15 \mathrm{~mL})$. The combined organic layers were then washed with sat. aq. $\mathrm{NaHCO}_{3}(1 \times 10 \mathrm{~mL})$ and brine $(1 \times 10 \mathrm{~mL})$, dried with 
$\mathrm{Na}_{2} \mathrm{SO}_{4}$, filtered, and concentrated. The resulting aldehyde was azeotroped from benzene three times and dissolved in THF $(1.5 \mathrm{~mL})$. To a separate flask charged with isopropyltriphenylphosphonium iodide $(160 \mathrm{mg}, 0.36 \mathrm{mmol})$ and THF $(6 \mathrm{~mL})$ at $-78{ }^{\circ} \mathrm{C}$ was added $2.5 \mathrm{M} \mathrm{n}$-BuLi $(130 \mu \mathrm{L}, 0.325 \mathrm{mmol})$ dropwise via syringe. The resulting orange solution was placed at room temperature for 5 minutes affording a color change to dark red. The reaction was then put back at $-78{ }^{\circ} \mathrm{C}$ and the aldehyde was added via cannula followed by a THF wash (500 $\mu \mathrm{L})$. The reaction was stirred at $-78^{\circ} \mathrm{C}$ for 30 minutes and then slowly warmed to $0{ }^{\circ} \mathrm{C}$ over 40 minutes. The reaction stirred at $0{ }^{\circ} \mathrm{C}$ for $1 \mathrm{~h}$ and then was quenched with sat. aq. $\mathrm{NaHCO}_{3}(5$ $\mathrm{mL})$, diluted with water $(15 \mathrm{~mL})$ and $\mathrm{Et}_{2} \mathrm{O}(30 \mathrm{~mL})$. The layers were separated and the aqueous layer was extracted wit $\mathrm{Et}_{2} \mathrm{O}(1 \times 15 \mathrm{~mL})$. The combined organic layers were washed with brine (10 $\mathrm{mL})$, dried with $\mathrm{MgSO}_{4}$, filtered, and concentrated. The crude reaction mixture was diluted with $\mathrm{CH}_{2} \mathrm{Cl}_{2}(15 \mathrm{~mL})$ and adsorbed onto $\mathrm{SiO}_{2}$ gel. The resulting solid was directly loaded onto a $\mathrm{SiO}_{2}$ gel column and was purified via flash chromatography $\left(1.2 \% \mathrm{Et}_{2} \mathrm{O} /\right.$ hexanes $)$ to yield $81 \mathrm{mg}$ (93\% yield over 2 steps) of the olefin as an oil: $[\alpha]_{\mathrm{D}}^{20}-0.33^{\circ}\left(c 0.6, \mathrm{CHCl}_{3} ;\right)^{1} \mathrm{H} \mathrm{NMR}(500 \mathrm{MHz}$, $\left.\mathrm{CDCl}_{3}\right) \delta 5.10(\mathrm{dd}, J=7.5,7.5 \mathrm{~Hz}, 1 \mathrm{H}), 4.16(\mathrm{~m}, 2 \mathrm{H}), 1.98(\mathrm{~m}, 2 \mathrm{H}), 1.77(\mathrm{~m}, 2 \mathrm{H}), 1.68(\mathrm{~s}, 3 \mathrm{H})$, $1.61(\mathrm{~s}, 3 \mathrm{H}), 1.35(\mathrm{~m}, 20 \mathrm{H}), 1.23(\mathrm{~s}, 3 \mathrm{H}), 1.19(\mathrm{~s}, 9 \mathrm{H}), 1.17(\mathrm{~s}, 3 \mathrm{H}), 1.16(\mathrm{~s}, 6 \mathrm{H}), 0.94(\mathrm{~m}, 36$ $\mathrm{H}), 0.57(\mathrm{~m}, 24 \mathrm{H}) ;{ }^{13} \mathrm{C}$ NMR $\left(100 \mathrm{MHz}, \mathrm{CDCl}_{3}\right) \delta 178.6,130.9,124.9,75.56,75.53,75.4,74.5$, $61.5,43.9,43.3,43.12,42.96,42.25,40.5,38.6,29.7,27.9,27.7,27.62,27.55,27.2,25.7,22.9$, $18.97,18.94,17.5,7.2,7.1,6.9,6.8$; high resolution mass spectrum (ES+) $\mathrm{m} / \mathrm{z} 988.8040$ $\left[\left(\mathrm{M}+\mathrm{NH}_{4}\right)^{+} ;\right.$calcd for $\left.\mathrm{C}_{54} \mathrm{H}_{118} \mathrm{O}_{6} \mathrm{Si}_{4} \mathrm{~N}: 988.8036\right]$. 


\section{Sulfone (-)-2}

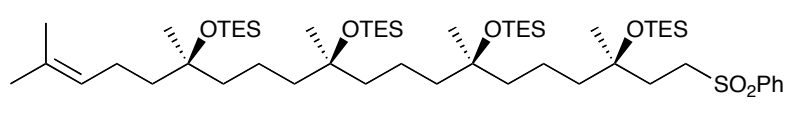

\section{$(-)-2$}

Sulfone (-)-2. $[\alpha]_{D}^{20}-0.45^{\circ}\left(c \quad 0.6,5 \mathrm{CH}_{2} \mathrm{Cl}_{2} ;\right)^{1} \mathrm{H}$ NMR $\left(500 \mathrm{MHz}, \mathrm{C}_{6} \mathrm{D}_{6}\right) \delta 7.89(\mathrm{~m}, 2 \mathrm{H})$, $6.95(\mathrm{~m}, 3 \mathrm{H}), 5.29(\mathrm{dd}, J=7.0,7.0 \mathrm{~Hz}, 1 \mathrm{H}), 3.22(\mathrm{~m}, 2 \mathrm{H}), 2.20(\mathrm{~m}, 2 \mathrm{H}), 1.96(\mathrm{~m}, 2 \mathrm{H}), 1.70$ (s , $3 \mathrm{H}), 1.65(\mathrm{~s}, 3 \mathrm{H}), 1.58(\mathrm{~m}, 14 \mathrm{H}), 1.41(\mathrm{~m}, 6 \mathrm{H}), 1.30(\mathrm{~s}, 3 \mathrm{H}), 1.25(\mathrm{~s}, 3 \mathrm{H}), 1.23(\mathrm{~s}, 3 \mathrm{H}), 1,09$ (app q, J = 7.5 Hz, 27 H), $0.99(\mathrm{~s}, 3 \mathrm{H}), 0.93(\operatorname{app~t}, J=7.5 \mathrm{~Hz}, 9 \mathrm{H}), 0.69(\mathrm{~m}, 18 \mathrm{H}), 0.51$ (m, 6 $\mathrm{H}) ;{ }^{13} \mathrm{C}$ NMR $\left(100 \mathrm{MHz}, \mathrm{C}_{6} \mathrm{D}_{6}\right) \delta 140.6,133.0,131.0,129.1,128.3,125.4,75.9,75.82,75.78$, 74.6, 52.6, 43.75, 43.67, 43.45, 43.27, 43.22, 42.8, 35.4, 28.0, 27.9, 27.4, 25.8, 23.5, 19.5, 19.2, $17.7,7.55,7.52,7.44,7.41,7.36,7.1$; high resolution mass spectrum (ES+) $\mathrm{m} / \mathrm{z} 1028.7439$ $\left[\left(\mathrm{M}+\mathrm{NH}_{4}\right)^{+}\right.$; calcd for $\mathrm{C}_{55} \mathrm{H}_{114} \mathrm{O}_{6} \mathrm{SSi}_{4} \mathrm{~N}:$ 1028.7444].

\section{Alcohol 5}

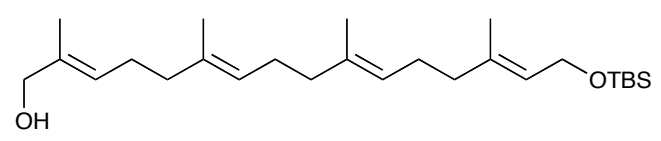

Alcohol 5. Alcohol 5 was prepared in accordance with the Sharpless protocol ${ }^{5}$ : ${ }^{1} \mathrm{H}$ NMR (500 MHz, $\left.\mathrm{CDCl}_{3}\right) \delta 5.40$ (dd, $\left.J=7.0,7.0 \mathrm{~Hz}, 1 \mathrm{H}\right), 5.31$ (dd, $\left.J=6.5,6.5 \mathrm{~Hz}, 1 \mathrm{H}\right), 5.12(\mathrm{~m}, 2 \mathrm{H})$, $4.20(\mathrm{~d}, J=6.5 \mathrm{~Hz}, 2 \mathrm{H}), 4.00(\mathrm{~s}, 2 \mathrm{H}), 2.06(\mathrm{~m}, 12 \mathrm{H}), 1.67$ (s, 3 H), $1.63(\mathrm{~s}, 3 \mathrm{H}), 1.60(\mathrm{~s}, 6 \mathrm{H})$, 1.25 (br s, $1 \mathrm{H}), 0.91$ (s, $9 \mathrm{H}), 0.07$ (s, $6 \mathrm{H}) ;{ }^{13} \mathrm{C}$ NMR (100 MHz, $\left.\mathrm{CDCl}_{3}\right) \delta$ 136.9, 135.1, 134.7, $134.5,126.2,124.5,124.4,124.0,69.0,60.3,39.7,39.5,39.3,26.6,26.3,26.2,26.0,18.4,16.4$, 15.99, 15.96, 13.6, -5.1; high resolution mass spectrum $(\mathrm{FAB}+) \mathrm{m} / \mathrm{z} 443.3326\left[(\mathrm{M}+\mathrm{Na})^{+}\right.$; calcd for $\left.\mathrm{C}_{26} \mathrm{H}_{48} \mathrm{O}_{2} \mathrm{SiNa}: 443.3322\right]$. 


\section{Preparation of Protected Glisoprenin A (+)-14}

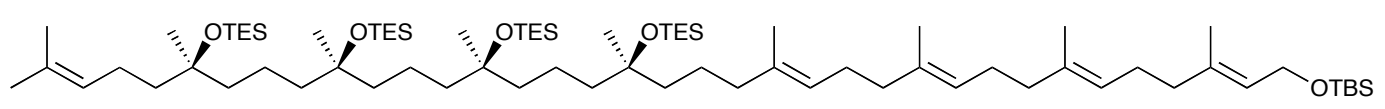

$(+)-14$

Preparation of Protected Glisoprenin A. To a solution of sulfone (-)-2 (65 mg, 0.064 mmol) in THF $(800 \mu \mathrm{L})$ and HMPA $(120 \mu \mathrm{L})$ at $-78^{\circ} \mathrm{C}$ was added $1.6 \mathrm{M} \mathrm{n}$-BuLi in hexanes (50 $\mu \mathrm{L}, 0.08 \mathrm{mmol}$ ) to yield a canary yellow color. The reaction mixture was allowed to stir for 20 minutes at which time a solution of chloride $3(44 \mathrm{mg}, 0.10 \mathrm{mmol})$, prepared from alcohol $5{ }^{6}{ }^{6}$ in THF (400 $\mu \mathrm{L})$ was added via cannula. After 30 minutes at $-78{ }^{\circ} \mathrm{C}$ the reaction was slowly warmed to ca. $-40^{\circ} \mathrm{C}$ over 40 additional minutes, and then the colorless reaction was brought to $0{ }^{\circ} \mathrm{C}$ and quenched with sat. aq. $\mathrm{NaHCO}_{3}(1 \mathrm{~mL})$. The reaction mixture was diluted with $\mathrm{Et}_{2} \mathrm{O}(30$ $\mathrm{mL})$ and $\mathrm{H}_{2} \mathrm{O}(10 \mathrm{~mL})$. The layers were separated and the aqueous layer was extracted with $\mathrm{Et}_{2} \mathrm{O}$ $(2 \times 10 \mathrm{~mL})$. The organic layers were combined and washed with brine $(10 \mathrm{~mL})$, dried with $\mathrm{MgSO}_{4}$, filtered and concentrated. Partial purification via $\mathrm{SiO}_{2}$ gel flash chromatography $(1.75 \%$ ethyl acetate/hexanes) followed by PTLC of the mixed fractions yielded $13 \mathrm{mg}$ of recovered sulfone (-)-2, $23 \mathrm{mg}$ of recovered chloride 3 and $68 \mathrm{mg} \mathrm{(75 \%} \mathrm{yield,} \mathrm{93 \%} \mathrm{BORSM)} \mathrm{of} \mathrm{the} \mathrm{desired}$ adduct as a diastereomeric mixture of sulfones.

The adduct prepared above (16 mg, $0.0113 \mathrm{mmol})$ was then dissolved in THF (400 $\mu \mathrm{L})$. A separate flask was charged with $5 \% \mathrm{Na} / \mathrm{Hg}$ amalgam beads [(Aldrich) $100 \mathrm{mg}, 0.217 \mathrm{mmol}$, $\mathrm{MeOH}(1.5 \mathrm{~mL})$, and $\mathrm{NaH}_{2} \mathrm{PO}_{4}(34 \mathrm{mg}, 0.238 \mathrm{mmol})$. To the resulting heterogeneous suspension was added the solution of the sulfone adduct via cannula, followed by a THF wash $(200 \mu \mathrm{L})$. The suspension was allowed to stir for $2.5 \mathrm{~h}$. The reaction was then diluted with $\mathrm{Et}_{2} \mathrm{O}$ and the reaction mixture was decanted into a brine solution $(10 \mathrm{~mL})$ leaving the residual $\mathrm{Hg}$ behind. The layers were separated and the aqueous layer was re-extracted with $\mathrm{Et}_{2} \mathrm{O}(2 \times 10 \mathrm{~mL})$. The combined organic layers were dried with $\mathrm{MgSO}_{4}$, filtered and concentrated. Purification via $\mathrm{SiO}_{2}$ gel flash chromatography (0.9\% $\mathrm{Et}_{2} \mathrm{O} /$ hexanes) yielded $13 \mathrm{mg}(92 \%$ yield) of protected glisoprenin $\mathrm{A},(+)-$ 
15, as an oil: $[\alpha]_{\mathrm{D}}^{20}+0.62^{\circ}\left(c 0.65, \mathrm{CH}_{2} \mathrm{Cl}_{2} ;\right)^{1} \mathrm{H}$ NMR $\left(500 \mathrm{MHz}, \mathrm{C}_{6} \mathrm{D}_{6}\right) \delta 5.54(\mathrm{dd}, J=5.9,5.9 \mathrm{~Hz}$, $1 \mathrm{H}), 5.30(\mathrm{~m}, 4 \mathrm{H}), 4.24(\mathrm{~d}, J=6.4 \mathrm{~Hz}, 2 \mathrm{H}), 2.14(\mathrm{~m}, 16 \mathrm{H}), 1.70(\mathrm{~s}, 3 \mathrm{H}), 1.68(\mathrm{~s}, 3 \mathrm{H}), 1.65$ (s 3 H), $1.64(\mathrm{~s}, 3 \mathrm{H}), 1.60(\mathrm{~m}, 23 \mathrm{H}), 1.54(\mathrm{~s}, 3 \mathrm{H}), 1.4-1.2(\mathrm{~m}, 16 \mathrm{H}), 1.10(\mathrm{~m}, 36 \mathrm{H}), 1.01(\mathrm{~s}, 9 \mathrm{H}), 0.7$ (m, $24 \mathrm{H}), 0.11(\mathrm{~s}, 6 \mathrm{H}) ;{ }^{13} \mathrm{C}$ NMR $\left(125 \mathrm{MHz}, \mathrm{C}_{6} \mathrm{D}_{6}\right) \delta 136.6,135.2,135.07,135.04,130.9,125.4$, $125.3,124.9,124.8,124.5,75.98,75.95,75.8,60.4,43.74,43.70,43.66,43.64,43.48,43.45$, $40.7,40.3,40.2,39.9,30.4,30.2,28.1,28.0,27.22,27.17,26.7,26.2,25.9,23.5,23.0,19.52$, $19.48,19.40,18.5,17.7,16.3,16.15,16.11,16 ., 7.58,7.56,7.54,7.45,7.42,-4.89$; low resolution mass spectrum (FAB+) $\mathrm{m} / \mathrm{z} 1296\left[(\mathrm{M}+\mathrm{Na})^{+}\right.$; calcd for $\left.\mathrm{C}_{75} \mathrm{H}_{152} \mathrm{O}_{5} \mathrm{Si}_{5} \mathrm{Na}: 1296\right]$.

\section{Preparation of Glisoprenin A}

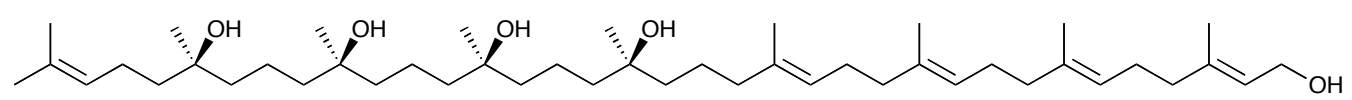

(+)-Glisoprenin A

Glisoprenin A. To a solution of adduct (+)-14 (30 mg, $0.0235 \mathrm{mmol})$ in THF (2.2 mL) at $0{ }^{\circ} \mathrm{C}$ was added $\mathrm{H}_{2} \mathrm{O}(160 \mu \mathrm{L})$ and then trifluoroacetic acid $(135 \mu \mathrm{L})$. The reaction mixture was brought to room temperature and permitted to stir for $3 \mathrm{~h}$. The reaction mixture was then filtered through a column of basic alumina (Brockmann type I) using gradient elution $(2.5 \rightarrow 7.5 \%$ $\mathrm{MeOH} / \mathrm{CH}_{2} \mathrm{Cl}_{2}$ ). The fractions of eluant containing synthetic glisoprenin A were concentrated and purified via $\mathrm{SiO}_{2}$ gel flash chromatography $\left(2.5 \rightarrow 7.5 \% \mathrm{MeOH} / \mathrm{CH}_{2} \mathrm{Cl}_{2}\right)$ to yield $16 \mathrm{mg}(96 \%$ yield) of synthetic glisoprenin A. ${ }^{1} \mathrm{H}$ NMR $\left(500 \mathrm{MHz}, \mathrm{CDCl}_{3}\right) \delta 5.35(\mathrm{dd}, J=6.4,6.4 \mathrm{~Hz}, 1 \mathrm{H}), 5.16-5.07$ (m, $4 \mathrm{H}), 4.07(\mathrm{~d}, J=6.4 \mathrm{~Hz}, 2 \mathrm{H}), 2.15-2.06(\mathrm{~m}, 8 \mathrm{H}), 2.05-1.95(\mathrm{~m}, 8 \mathrm{H}), 1.66(\mathrm{~s}, 6 \mathrm{H}), 1.613(\mathrm{~s}$, $3 \mathrm{H}), 1.606$ (s $3 \mathrm{H}), 1.59(\mathrm{~s}, 6 \mathrm{H}), 1.45-1.28(\mathrm{~m}, 24 \mathrm{H}), 1.14(\mathrm{~s}, 9 \mathrm{H}), 1.13(\mathrm{~s}, 3 \mathrm{H}) ;{ }^{13} \mathrm{C}$ NMR $(100$ $\left.\mathrm{MHz}, \mathrm{CD}_{3} \mathrm{OD}\right) \delta 139.4,136.2,135.92,135.86,132.0 ; 125.8,125.6,125.5,125.3,124.9,73.45$ 73.38, 73.32, 59.4, 43.42, 43.36, 43.29, 42.7, 42.2, 41.3, 40.9, 40.8, 27.7, 27.5, 27.04, 26.98, $26.91,25.92,23.7,23.3,19.4,17.7,16.3,16.15,16.13,16.0$; high resolution mass spectrum (ES+) $m / z 703.6238\left[(\mathrm{M}+\mathrm{H})^{+} ;\right.$calcd for $\left.\mathrm{C}_{45} \mathrm{H}_{83} \mathrm{O}_{5}: 703.6240\right]$. 
${ }^{1}$ (a) Katsuki, T.; Sharpless, K. B. J. Am. Chem. Soc. 1980, 102, 5974. (b) Gao, Y.; Hanson, R. M.; Klunder, J. M.; Ko, S. Y.; Masamune, H.; Sharpless, K. B. J. Am. Chem. Soc. 1987, 109, 5765.

${ }^{2}$ Corey, E. J.; Zhang, J. Organic Lett. 2001, 3, 3211.

${ }^{3}$ The ligand used for this reaction was generously provided by Professor E. J. Corey.

${ }^{4}$ Wang, Z.-X.; Tu, Y.; Frohn, M.; Zhang, J.-R.; Shi, Y. J. Am. Chem. Soc. 1997, 119, 11224.

${ }^{5}$ Umbreit, M. A.; Sharpless, K. B.; J. Am. Chem. Soc. 1977, 99, 5526.

${ }^{6}$ Chloride 3 was prepared in $86 \%$ yield via the protocol developed by Collington and Meyers, see:

Collington, E. W.; Meyer, A. I. J. Org. Chem. 1971, 36, 3044. 


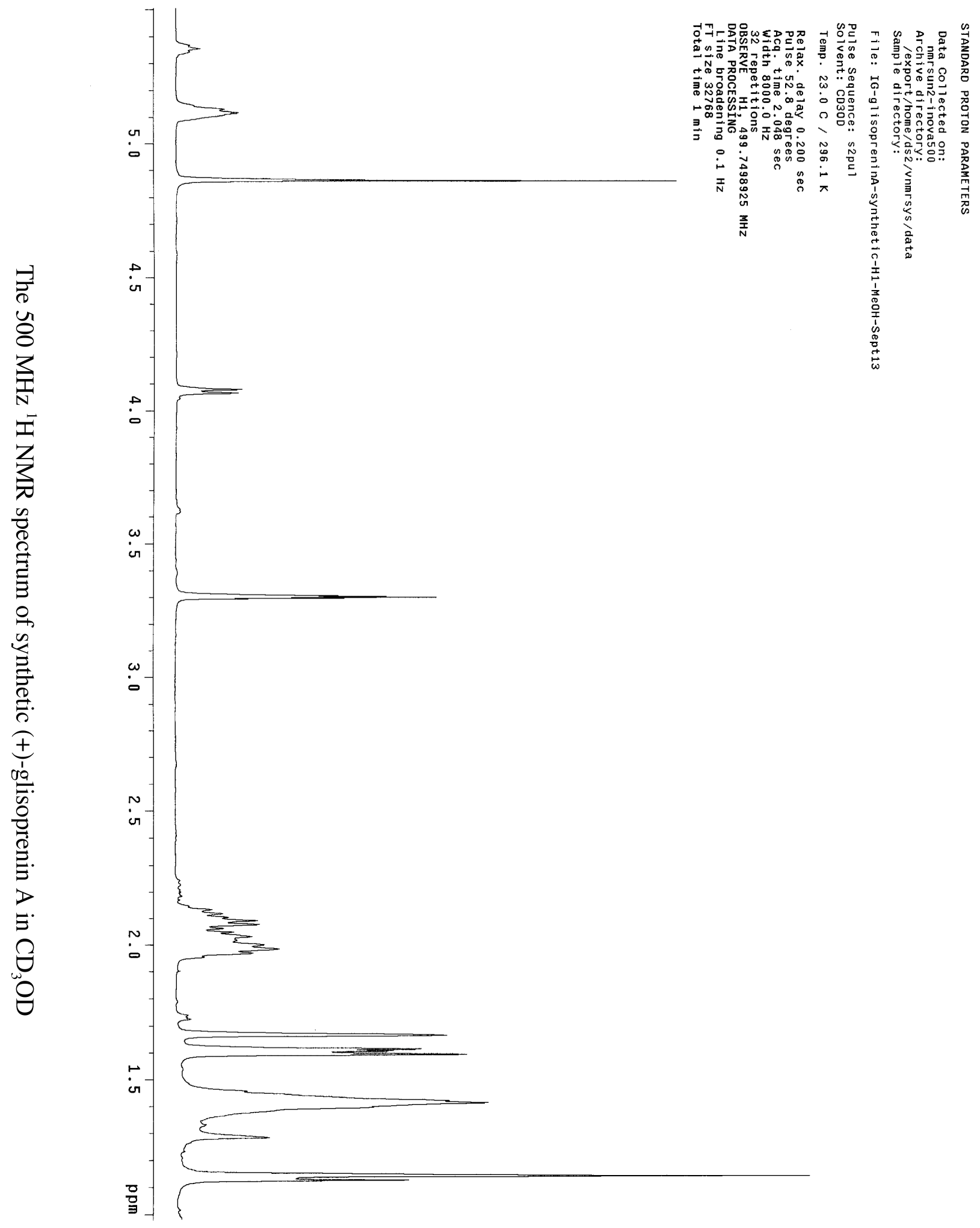




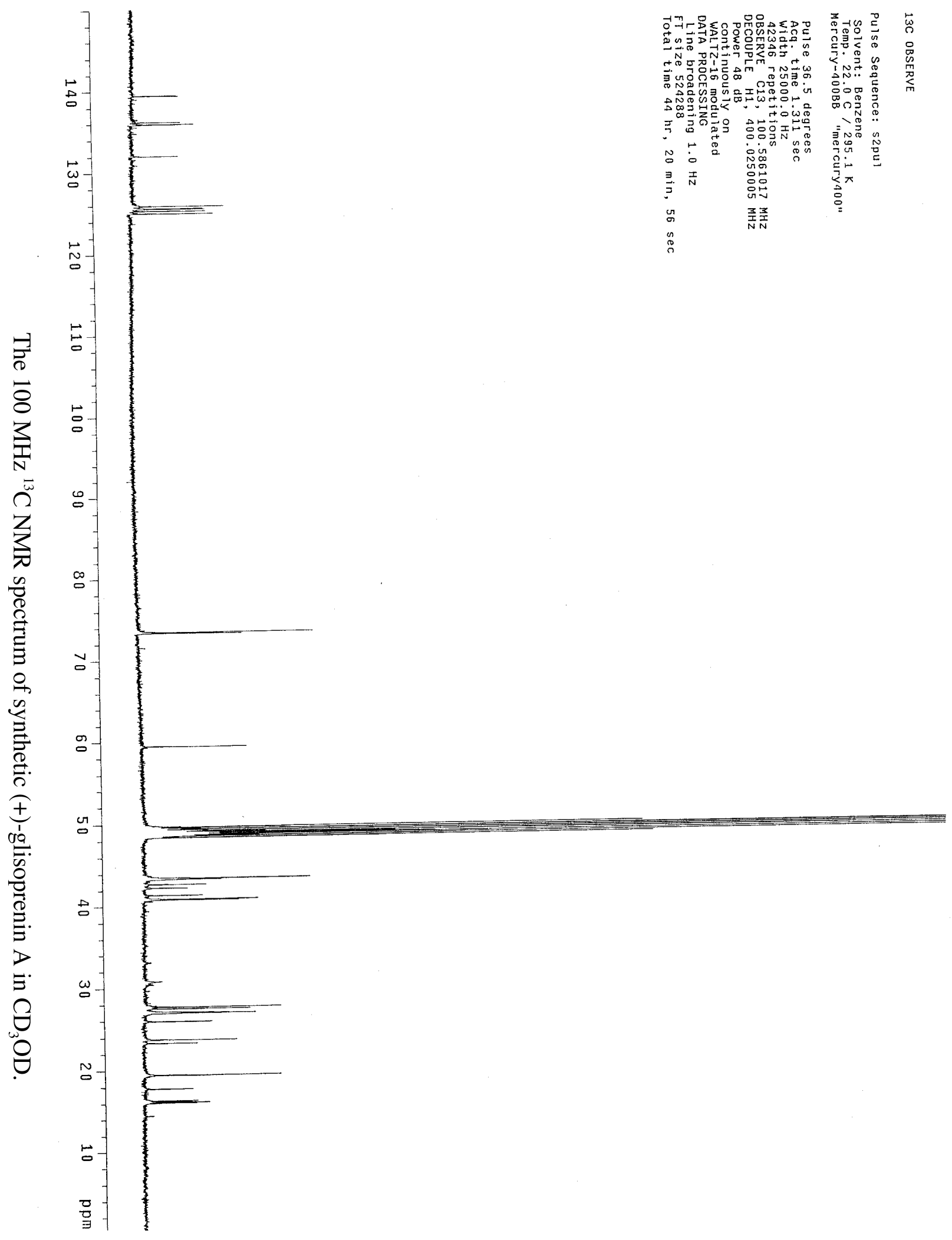




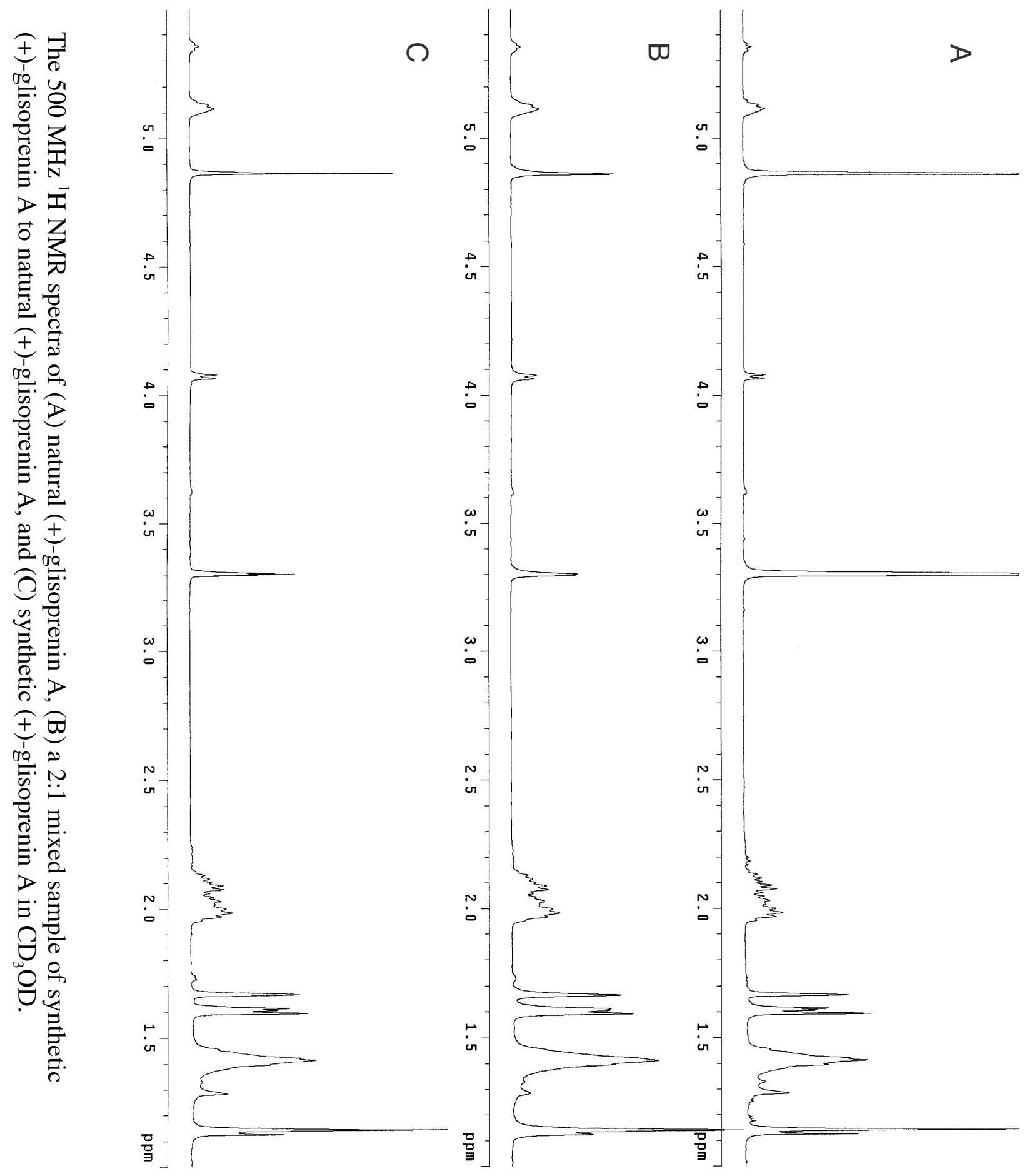




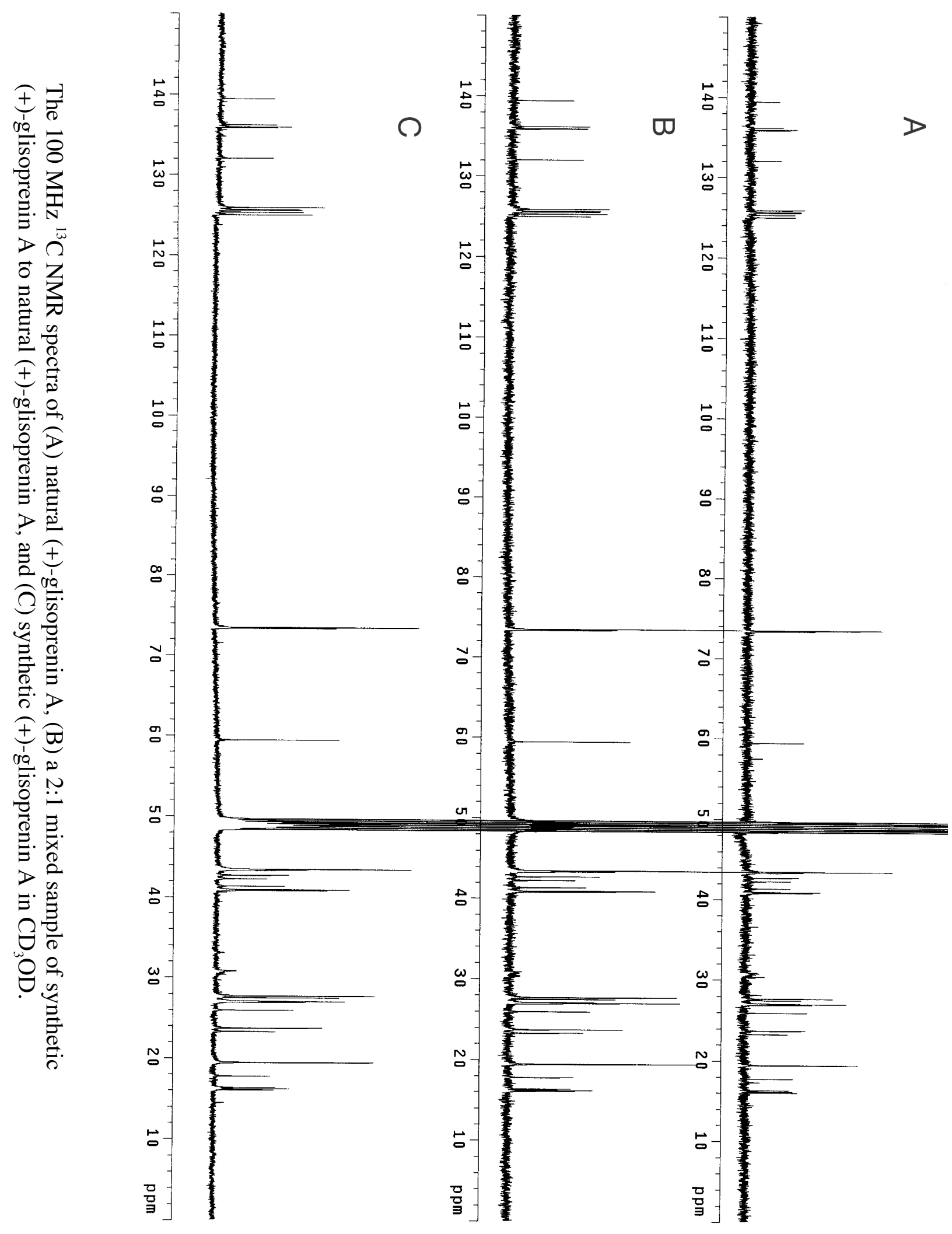



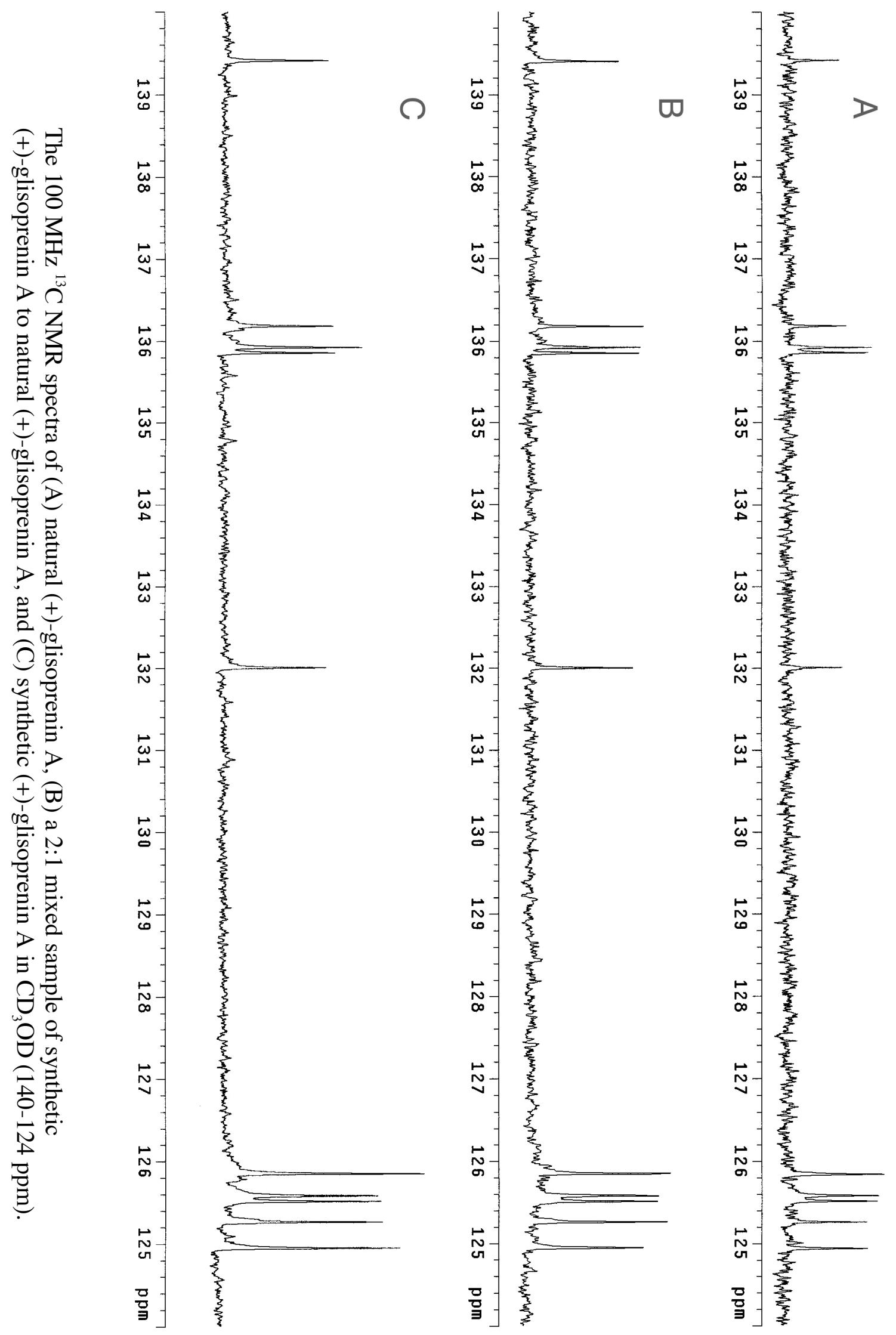


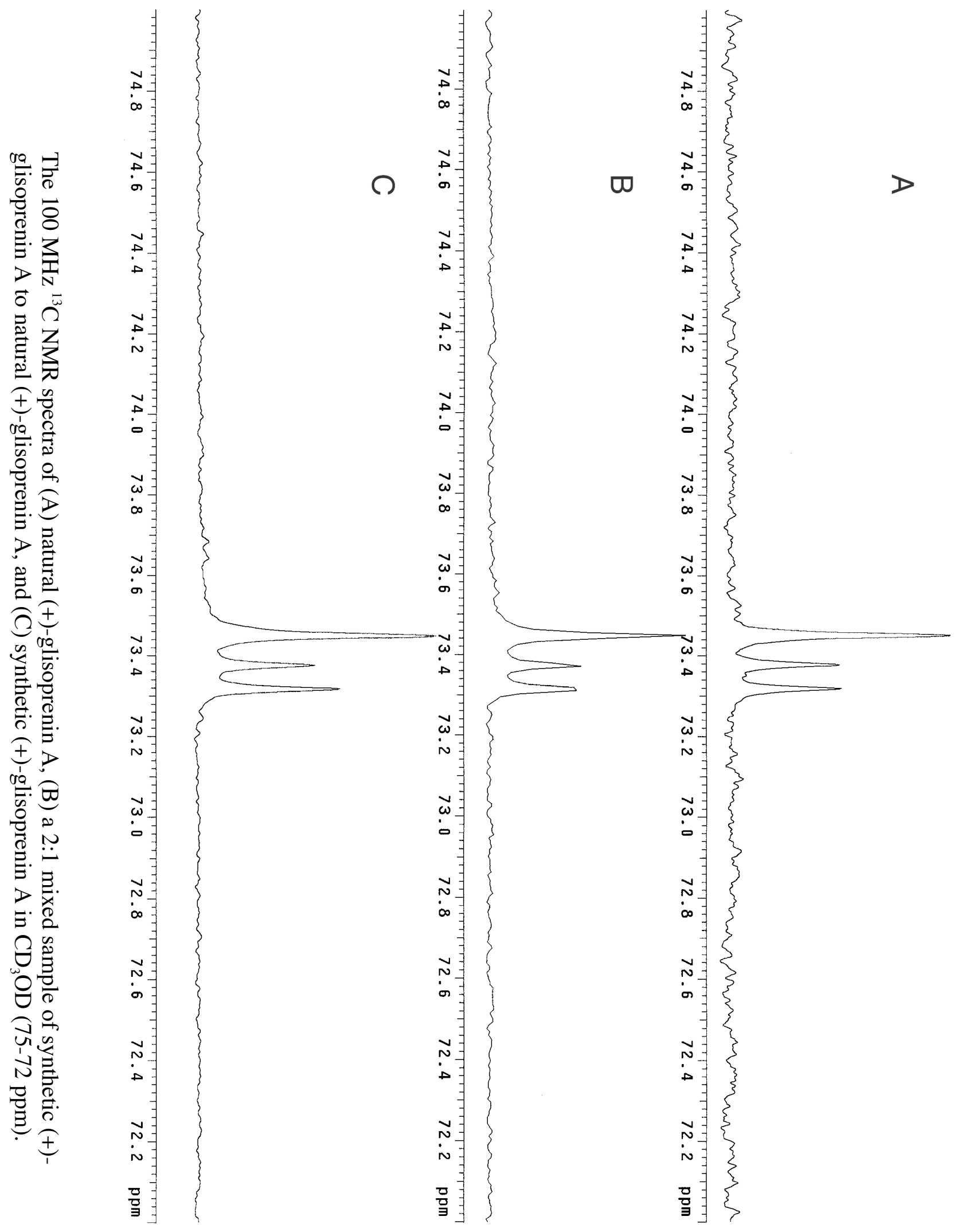




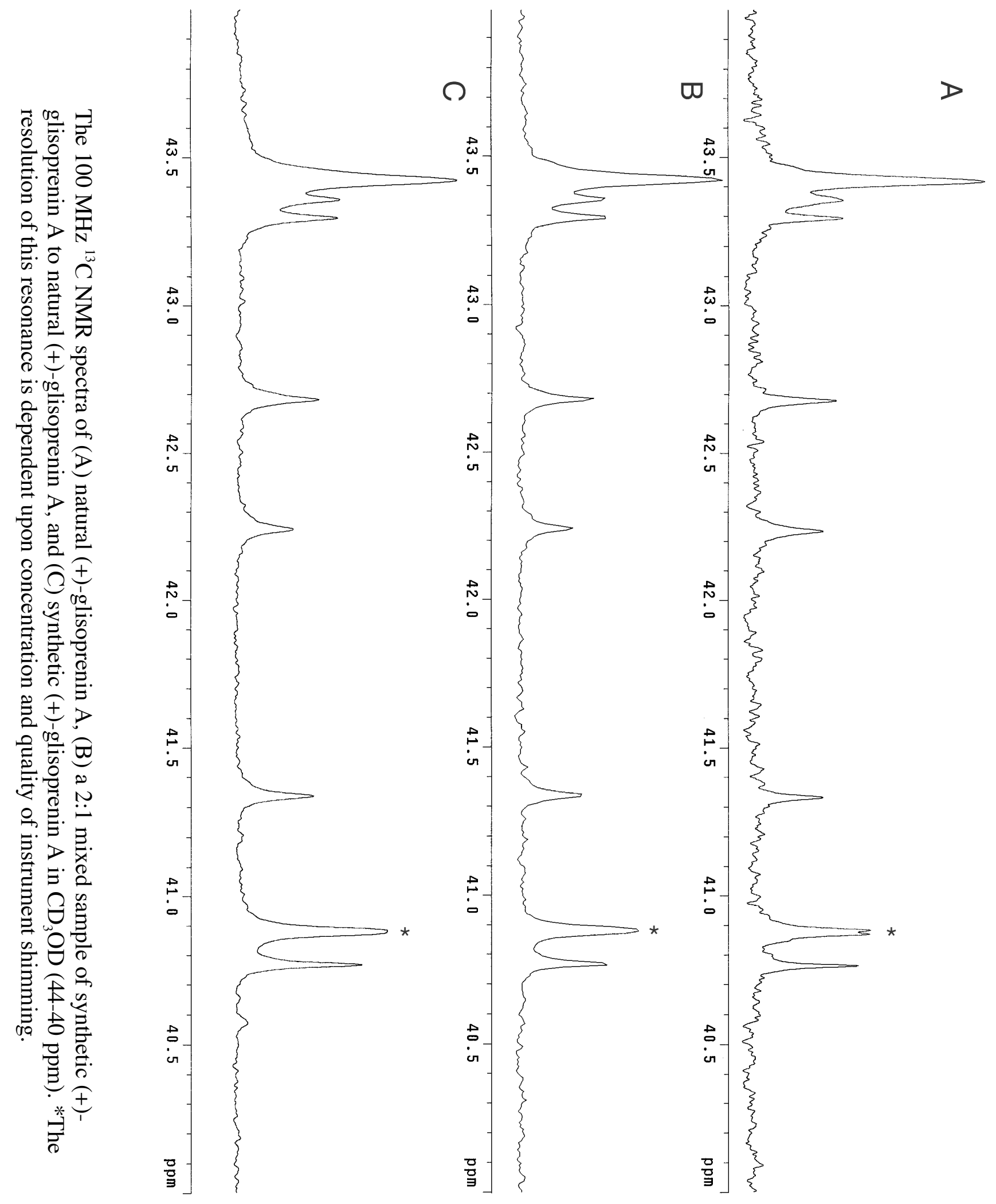



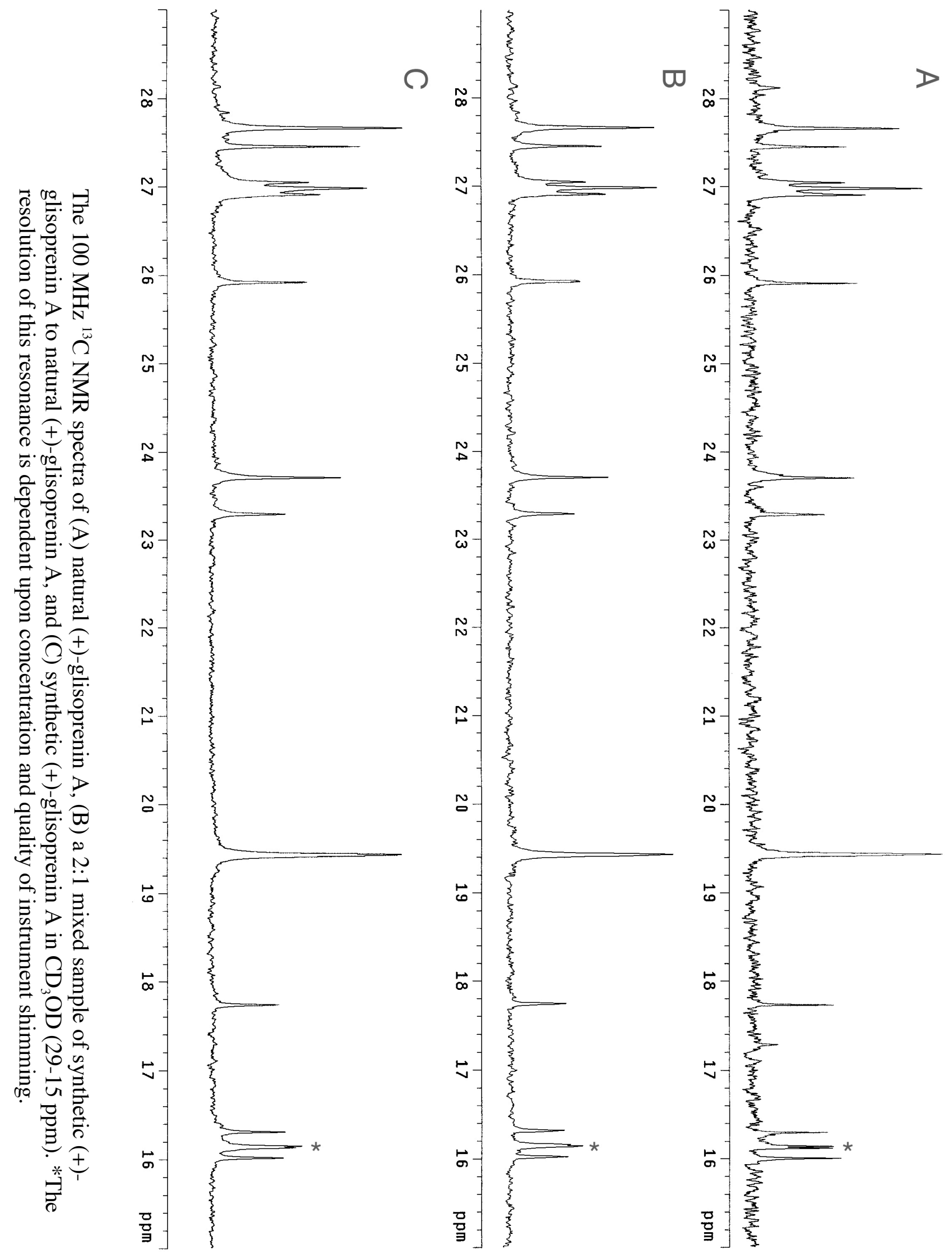


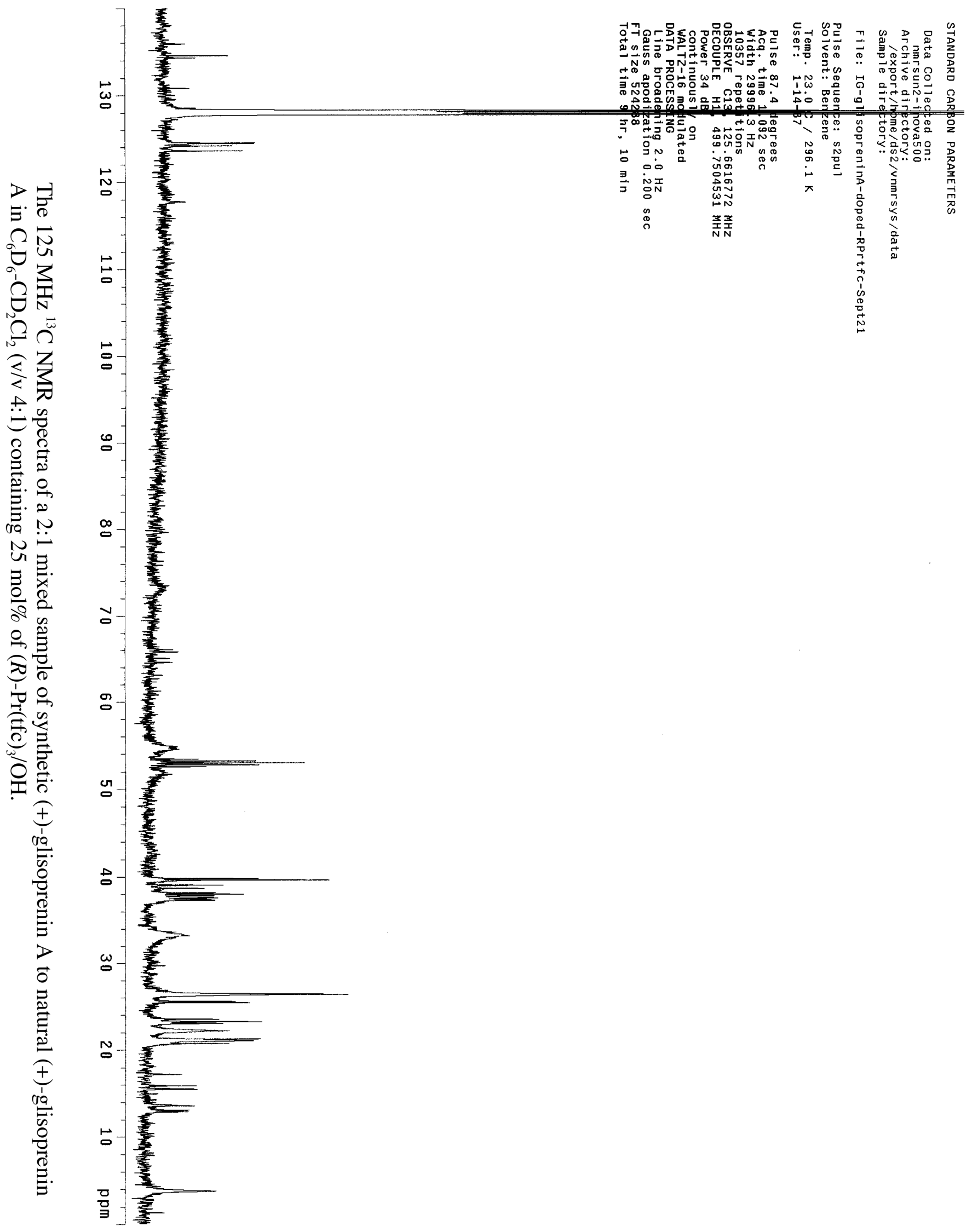



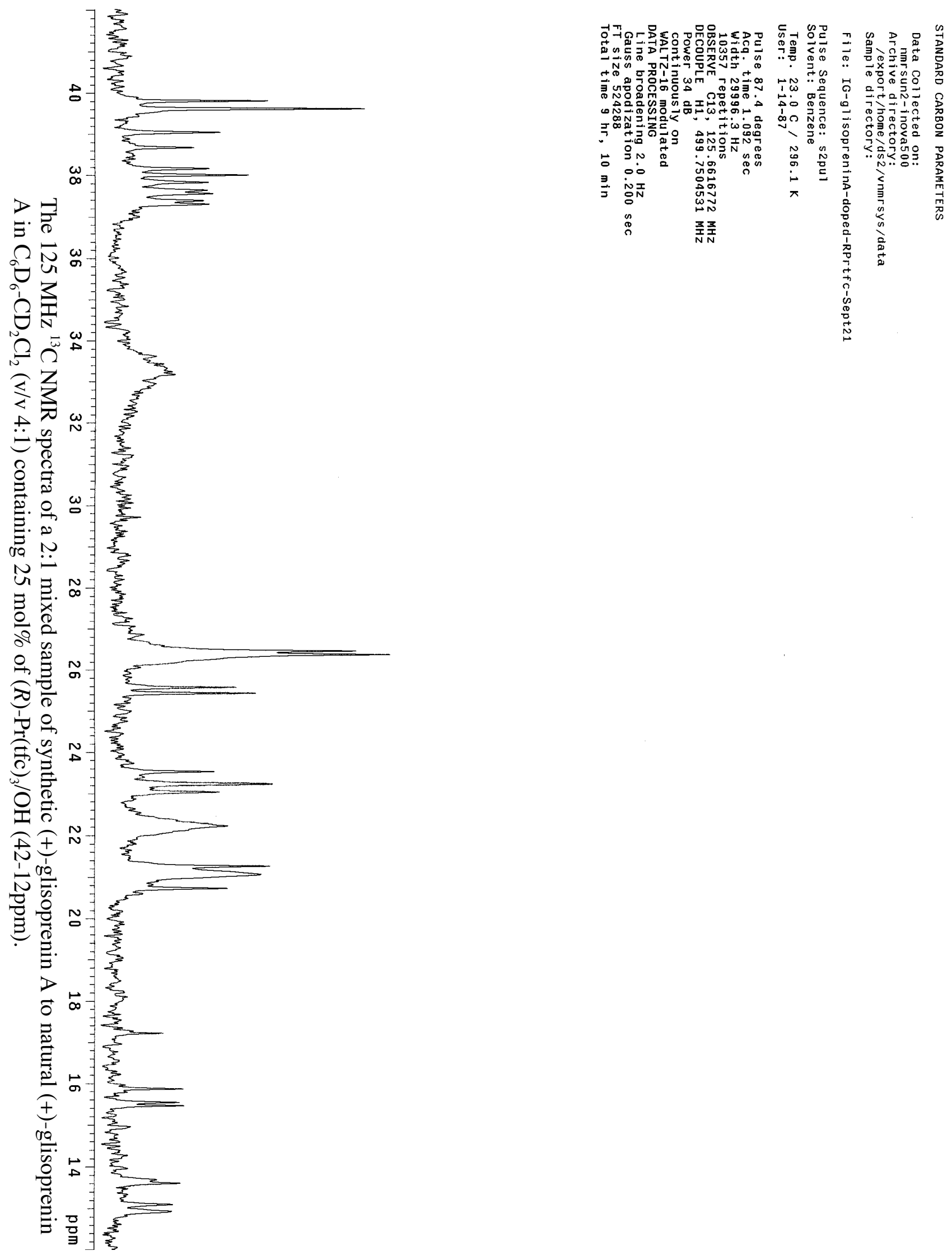


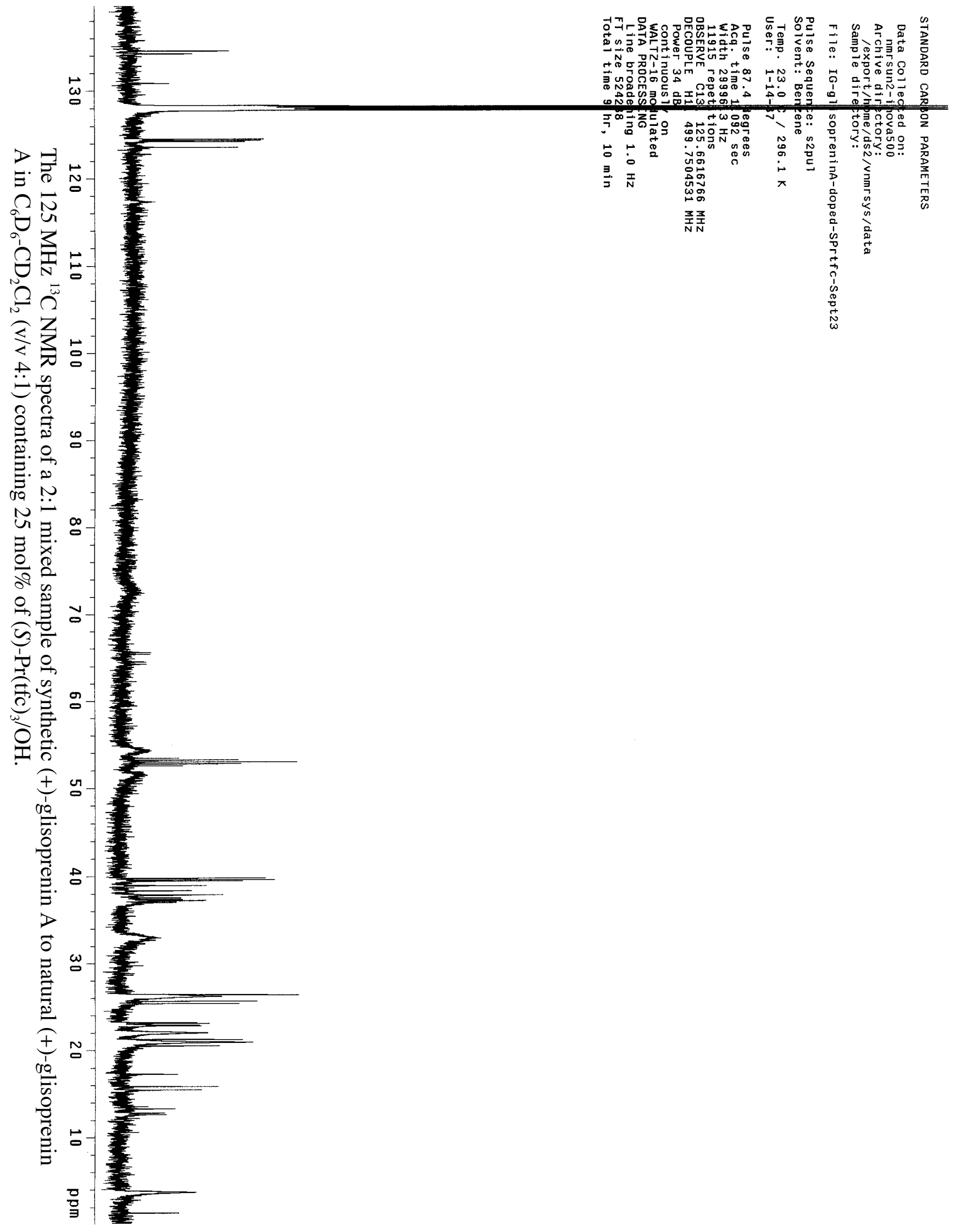



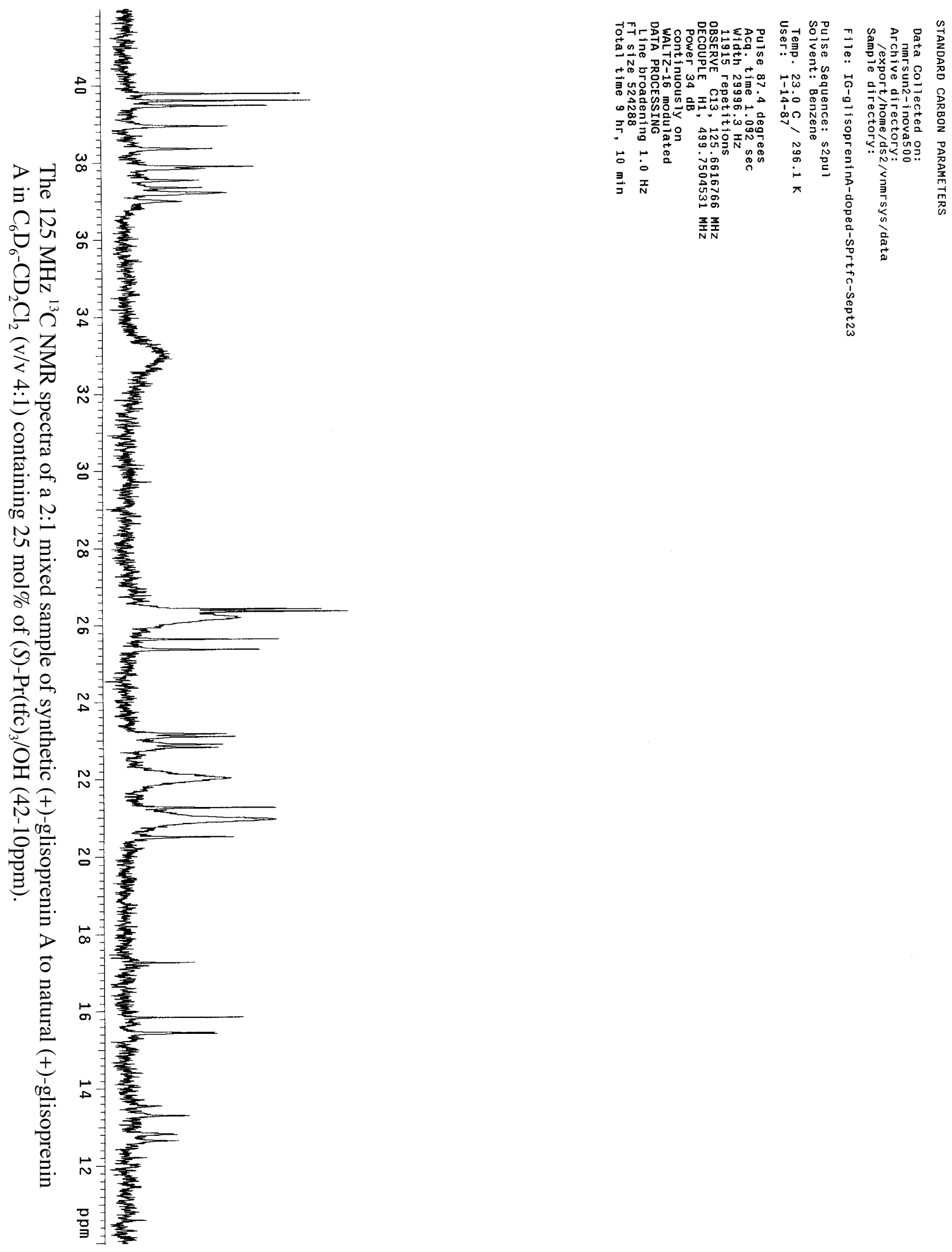


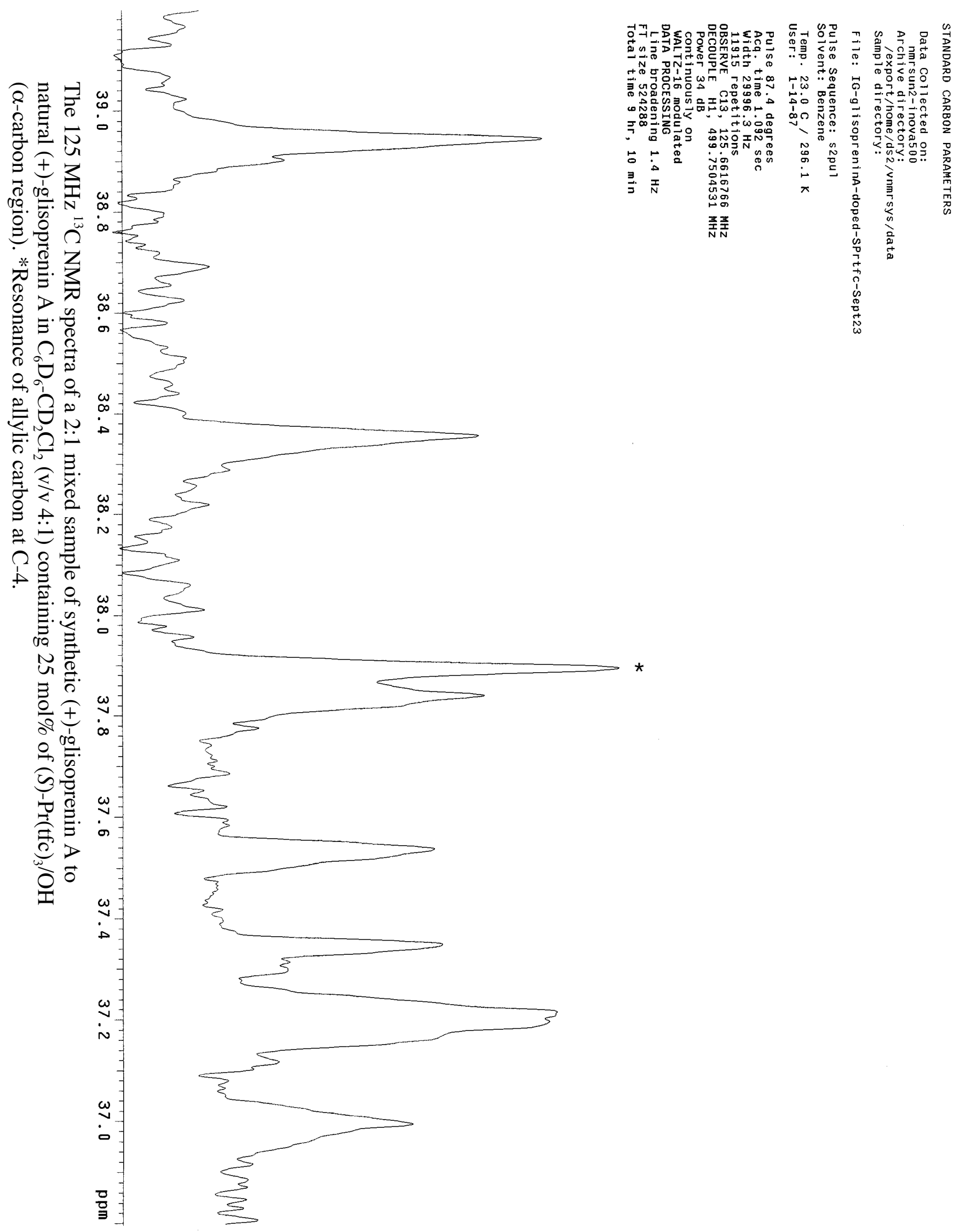

